VIII Congresso Brasileiro de Informática na Educação (CBIE 2019)

Anais do XXV Workshop de Informática na Escola (WIE 2019)

\title{
Aprendizagem Criativa nas escolas brasileiras
}

\author{
Valeria C. Gomes Leal, Marcos Augusto F. Borges \\ Faculdade de Tecnologia - Universidade Estadual de Campinas (UNICAMP) \\ Caixa Postal 15.064 - 91.501-970 - Limeira - SP - Brasil \\ vckawauchi@hotmail.com, marcosborgeseft.unicamp.br
}

\begin{abstract}
New approaches to teaching have been disseminated throughout history. The Creative Learning approach emphasizes the value of children in creating play while developing meaningful projects for them with peer collaboration. This paper proposes to investigate whether Brazilian schools have been working on the Creative Learning approach and whether these projects can serve as an expiration for other educators.
\end{abstract}

Resumo. Novas abordagens de ensino vêm sendo disseminadas ao longo da história. A abordagem Aprendizagem Criativa, enfatiza o valor das crianças em criar brincando, enquanto desenvolvem projetos significativos para elas com a colaboração dos colegas. Este trabalho propôs pesquisar se as escolas brasileiras estão trabalhando a abordagem Aprendizagem Criativa e estes projetos podem servir de inspiração para outros educadores.

\section{Introdução}

Várias abordagens de ensino foram disseminadas ao longo da história da educação. $\mathrm{O}$ método do ensino Construcionista, iniciado por Seymour Papert (1993), propõe que sejam fornecidas as ferramentas necessárias para que as crianças possam descobrir e explorar o conhecimento. O método Construcionista vem sendo estudado nos últimos anos por Michel Resnick, pesquisador do Lifelong Kindergarten do Media Lab, do Massachusetts Institute of Technology (MIT). Ao longo de suas pesquisas, Resnick propôs a abordagem Aprendizagem Criativa (AC), que está fortemente alinhada com o método Construcionista de Seymour Papert, enfatizando o valor das crianças em criar brincando, enquanto desenvolvem projetos significativos para elas com a colaboração dos colegas (RESNICK, 2017).

\section{Objetivos}

Este trabalho tem por objetivo pesquisar e identificar projetos e experiências nas escolas brasileiras que utilizam a abordagem AC. Verificar se estes projetos tem detalhamento suficiente para que possam ser replicados por outros educadores ou servir de inspiração. AC pode ser trabalhada com vários temas e ferramentas, este trabalho foca o uso de uma única ferramenta para poder comparar semelhanças ou particularidades nos projetos.

\section{Embasamento Teórico}

Resnick (2017) acredita na importância da criação para que as crianças se desenvolvam como pensadores criativos. Para atender esta nova abordagem, Resnick e seu grupo de pesquisadores desenvolveram novas estratégias de ensino e tecnologias, que foram 
VIII Congresso Brasileiro de Informática na Educação (CBIE 2019)

Anais do XXV Workshop de Informática na Escola (WIE 2019)

agrupadas na abordagem de $\mathrm{AC}$ que é baseada em quatro elementos principais, chamados os quatro Ps da AC, que são definidos por Resnick (2017) como:

Projetos (projects): as pessoas aprendem melhor quando estão trabalhando em projetos que sejam significativos para elas, gerando novas ideias, criando protótipos, melhorando e criando produtos finais; Paixão (passion): quando as pessoas trabalham em projetos que lhes interessam, trabalham mais e persistem em enfrentar desafios e aprendem mais no processo; Pares (pair): o aprendizado é positivamente impactado quando é parte de uma atividade social, com pessoas compartilhando ideias, colaborando em projetos, e colaborando no trabalho uns dos outros; Brincar (play): o aprendizado envolve uma experimentação lúdica, tentar coisas novas, mexer com materiais, testar fronteiras, assumir riscos, fazer repetidas vezes.

\section{Métodos e Ferramentas}

Para analisar se AC está sendo trabalhada nas escolas brasileiras foi realizada uma pesquisa sistemática com foco em projetos realizados no Ensino Fundamental que usam especificamente a ferramenta Scratch $^{1}$.

As questões da pesquisa são: QP1- Qual a metodologia utilizada nestes projetos? / QP2- Os resultados obtidos foram os esperados? / QP3- Estes projetos tem detalhamento suficiente, que possibilitam a replicação do projeto por outros educadores?

Dado o enfoque brasileiro da pesquisa, as fontes de buscas escolhidas foram eventos e periódicos do Brasil voltados para educação e informática. A pesquisa ocorreu nos anais do Simpósio Brasileiro de Informática na Educação (SBIE/ CBIE), Workshop de Informática na Escola (WIE/ CBIE), Workshop sobre Educação em Informática (WEI/ CSBC) e Revista Brasileira de Informática na Educação.

O período definido para a pesquisa foi do ano de 2012 até 2016. A pesquisa realizada usou as palavras chaves: Scratch, Programação no Ensino Fundamental e Raciocínio Lógico. Os critérios de inclusão e exclusão dos artigos encontram-se na tabela 1 .

Tabela 1 - Critérios de Inclusão e Exclusão dos artigos

\begin{tabular}{|l|l|}
\hline \multicolumn{1}{|c|}{ Critérios de inclusão } & \multicolumn{1}{c|}{ Critérios de Exclusão } \\
\hline Artigos completos & Revisão sistemática da literatura \\
\hline Projetos envolvendo alunos do Ensino Fundamental & Estudos realizados em países que não o Brasil \\
\hline $\begin{array}{l}\text { Artigos que abordem pelo menos uma prática } \\
\text { didática usando a ferramenta Scratch }\end{array}$ & Estudos realizados no Ensino Médio ou Superior \\
\hline $\begin{array}{l}\text { Artigo possuir detalhamento do projeto que } \\
\text { possibilite sua replicação }\end{array}$ & Estudos que não usam a ferramenta Scratch \\
\hline
\end{tabular}

No total de 98 trabalhos pesquisados, vinte e um (21) trabalhos apresentaram projetos que trabalhavam com a ferramenta Scratch no Ensino Fundamental no Brasil, sendo esses os trabalhos considerados neste estudo.

\footnotetext{
${ }^{1}$ www.scratch.mit.edu
} 
VIII Congresso Brasileiro de Informática na Educação (CBIE 2019)

Anais do XXV Workshop de Informática na Escola (WIE 2019)

Durante a análise dos dados observaram-se algumas semelhanças ou particularidades nos artigos selecionados, o que possibilitou algumas análises dos dados agrupando os artigos conforme as particularidades encontradas.

Em vários trabalhos, o ensino da Lógica de Programação usando a ferramenta Scratch foi um projeto multidisciplinar e inserido nos componentes curriculares, sendo desenvolvidos durante o horário de aula, pelos professores polivalentes ou especialistas da sala de aula (JANELA, 2012; RABÊLO et al., 2015; WANGENHEIM, NUNES, et al., 2014). Estes projetos criam uma nova forma de utilização dos recursos de informática nas escolas e auxiliam diversas áreas do conhecimento.

O ambiente de programação Scratch também é utilizado no ensino da matemática, utilizando a programação de computadores na resolução de desafios, jogos e animações, trabalhando conceitos da matemática (TEIXEIRA, ORO, et al., 2015; ANDRADE, SILVA e OLIVEIRA, 2013).

$\mathrm{Na}$ metodologia de ensino aprendizagem "aprender fazendo e aprender brincando" usada no trabalho de Batista e Chalegre (2015) foram propostos desafios e jogos aos participantes e estes responderam aos desafios através de descobertas no ambiente Scratch, construindo programas por tentativa e erro. No trabalho de Oliveira, Souza et al (2014), as aulas tinham um caráter teórico/prático: Criando jogos simples e animações, os estudantes foram estimulados a desenvolver habilidades tanto por descoberta, quanto por meio de atividades direcionadas pelos ministrantes.

Em alguns trabalhos os projetos foram realizados em formatos de minicurso ou extensão no contra turno das aulas e os conceitos apresentados não estavam vinculados ao currículo escolar. Esses trabalhos tinham por objetivo estimular e desenvolver o raciocínio lógico nos alunos, ensinando lógica de programação (LEAL, BORGES e OLIVEIRA, 2016; FRANÇA, SILVA e AMARAL, 2012; SOUZA e MOMBACH, 2016; ARAÚJO, RODRIGUES, et al., 2015; SOUZA, RIOS, et al., 2015; RODRIGUES, QUEIROGA, et al., 2016).

Alguns projetos pesquisados demonstraram que o ambiente Scratch também pode ser utilizado em conjuntos com outros softwares e sites (SOBREIRA, VIVEIRO e D'ABREU, 2016; MARTINS, BRELAZ, et al., 2016; BEZERRA e DIAS, 2014) e disciplinas que não são da área de exatas como é o caso do projeto de Silva, Moraes e Batista, 2014 no qual os alunos trabalharam os conceitos de Saneamento Básico.

Para responder a QP1, verificou-se que cada projeto pesquisado pode ter um formato de aplicação e método específico: projeto multidisciplinar e inserido nos componentes curriculares; projeto em formato de extensão no contra turno das aulas com conceitos não vinculados ao currículo escolar; método de aprendizagem por tentativa e erro; aulas com caráter teórico/prático e atividades direcionadas pelos ministrantes. A resposta para a QP2 é positiva: em todos os trabalhos pesquisados, os autores observaram que os alunos demonstraram um aumento na motivação, acréscimo de interesse na área de computação, maior concentração e aumento da autoestima. Os alunos aprenderam competências em várias áreas do saber e foram estimulados o raciocínio lógico, o trabalho em grupo, a responsabilidade, a criatividade e a autonomia. Em todos os projetos os alunos participantes conseguiram desenvolver o conteúdo estabelecido, mostrando que é possível trabalhar no Ensino Fundamental abordagens e 
VIII Congresso Brasileiro de Informática na Educação (CBIE 2019)

Anais do XXV Workshop de Informática na Escola (WIE 2019)

ferramentas diferentes. A QP3 tem resposta positiva, pois ter detalhamento do projeto para que o mesmo possa ser replicado é um dos critérios de inclusão na pesquisa. Todos os projetos pesquisados podem ser replicados por terem detalhado suas metodologias.

\section{Conclusão}

Este trabalho teve a finalidade de compreender se AC está sendo trabalhada nas escolas. As pesquisas resultantes mostraram não haver uma padronização nos projetos quanto a métodos e características de seus conteúdos, mas foi possível perceber a variedade de temas abordados, a integração de diferentes disciplinas em um mesmo projeto, o trabalho em grupo, o compartilhamento de experiências, os diferentes perfis e interesses dos alunos e professores, a criação de jogos, histórias, animações e vários outros itens desenvolvido pelos alunos. Conclui-se que todos os projetos trabalharam características de $\mathrm{AC}$ e que os alunos aprenderam criando de forma lúdica.

\section{Referencias}

ANDRADE, M.; SILVA, C.; OLIVEIRA, T. Desenvolvendo games e aprendendo matemática utilizando o Scratch.. SBC - Proceedings of SBGames, São Paulo, 2013.

ARAÚJO, D. D. C. et al. O Ensino de Computação na Educação Básica apoiado por Problemas: Práticas de Licenciandos em Computação. Workshop sobre Educação em Computação - WEI, Recife, 2015.

BATISTA, W. P. et al. Oficinas de Aprendizagem de Programação em uma Escola Publica através do Ambiente Scratch'. Workshop sobre Educação em Informática WEI, Recife, 2015.

BEZERRA, F.; DIAS, K. Programação de Computadores no Ensino Fundamental: Experiências com Logo e Scratch em Escola Pública. XXXIV Congresso da Sociedade Brasileira de Computação, 2014.

FRANÇA, R. S. D.; AMARAL, H. J. C. D. Proposta Metodológica de Ensino e Avaliação para o Desenvolvimento do Pensamento Computacional com o Uso do Scratch. II Congresso Brasileiro de Informática na Educação, 2013.

FRANÇA, R. S. D.; SILVA, W. C. D.; AMARAL, H. J. C. D. Ensino de Ciência da Computação na Educação Básica: Experiências, Desafios e Possibilidades. XX Workshop sobre Educação em Informática, 2012.

JANELA, V. Reflexão Critica - Scratch num percurso curricular alternativo. EduScratch, 06 Fevereiro 2012.

LEAL, V. C. G.; BORGES, M. A. F.; OLIVEIRA, A. Despertando para a Programação com a Criação de Jogos. V Congresso Brasileiro de Informática na Educação (CBIE), Uberlândia, 2016.

MARTINS, L. A. D. S. et al. Ensinando Lógica de Programação aplicada à Robótica para alunos do Ensino Fundamental. Anais do XXVII Simpósio Brasileiro de Informática na Educação - SBIE , Uberlândia, 2016. 
VIII Congresso Brasileiro de Informática na Educação (CBIE 2019)

Anais do XXV Workshop de Informática na Escola (WIE 2019)

OLIVEIRA, M. L. S. D. et al. Ensino de lógica de programação no ensino fundamental utilizando o Scratch: um relato de experiência. XXXIV Congresso da Sociedade Brasileira de Computação - CSBC, Brasília, 2014.

ORO, N. T. et al. A Olimpíada de Programação de Computadores para Estudantes do Ensino Fundamental: A interdisciplinaridade por meio do software Scratch. CBIELACLO - Anais do XXI Workshop de Informática na Escola - WIE, Recife, 2015.

PAPERT, S. A Máquina das Crianças: Repensando a Escola na Era da Informática. Porto Alegre: Artmed, 1993.

RABÊLO, H. D. M. et al. Scratch na produção de recursos interdisciplinares com disciplinas indígenas. Workshop sobre Educação em Informática - WEI, Recife, 2015 .

RESNICK, M. Lifelong Kindergarten. In: RESNICK, M. Lifelong Kindergarten Cultivating Creativity through Projects, Passion, Peers, and Play. [S.1.]: Hardcover, 2017. p. 50,51,52.

RODRIGUES, L. C. et al. Relato de experiência: curso de introdução à programação para crianças do ensino fundamental no IFSP Votuporanga. XXII Workshop de Informática na Escola - WIE, Uberlândia, 2016.

SHIMOHARA, C.; SOBREIRA, E. S. R. Criando Jogos Digitais para a aprendizagem de matemática no ensino fundamental I. XXI Workshop de Informática na Escola WIE, Maceio, Outubro 2015.

SILVA, A. M. D. S.; MORAES, D. A. S. D. S.; BATISTA, S. C. F. Educação ambiental: Scratch como ferramenta pedagógica no ensino de saneamento básico. Revista Novas Tecnologias na Educação - RENOTE, v. 12, 2014.

SOBREIRA, E. S. R.; VIVEIRO, A. A.; D'ABREU, J. V. V. Do Paper Circuit à programação de Arduino com Scratch:uma sequência didática para aprendizagem do conteúdo de energia nos anos iniciais do Ensino Fundamental. Anais do XXII Workshop de Informática na Escola - WIE, Uberlândia, 2016.

SOUZA, P. S. S. D.; MOMBACH, J. G. Ensino de Programação para Crianças através de Práticas Colaborativas nas Escolas. Anais do XXII Workshop de Informática na Escola - WIE, Uberlândia, 2016.

SOUZA, S. M. et al. Oficinas de Programação com Ambientes Lúdicos para Meninas do Ensino Fundamental. Workshop sobre Educação em Computação - WEI, Recife, 2015.

TEIXEIRA, A. C. et al. Programação de computadores para alunos do ensino fundamental: A Escola de Hackers. XXI Workshop de Informática na Escola - WIE, Recife, 2015. p. 112.

WANGENHEIM, C. G. V.; NUNES, V. R.; SANTOS, G. D. D. Ensino de Computação com SCRATCH no Ensino Fundamental - Um Estudo de Caso. Revista Brasileira de Informática na Educação, Volume 22, n. Número 3, 2014. 